\title{
Relationship between body weight and leptin concentrations in mink dams and the birth parameters of kits
}

\author{
MONIKA BRYL, HANNA BIS-WENCEL, BRYGIDA ŚLASKA*, \\ BOŻENA NOWAKOWICZ-DĘBEK, ZBIGNIEW BEŁKOT*, AGNIESZKA KUBIK-KOMAR ${ }^{* * *}$
}

\author{
Department of Animal and Environment Hygiene, *Department of Biological Bases of Animal Production, \\ Faculty of Biology and Animal Breeding, University of Life Sciences in Lublin, Akademicka 13, 20-950 Lublin \\ **Department of Food Hygiene, Faculty of Veterinary Medicine, University of Life Sciences in Lublin, \\ Akademicka 12, 20-033 Lublin \\ ***Department of Applied Mathematics and Computer Science, Faculty of Production Engineering, \\ University of Life Sciences in Lublin, Głęboka 28, 20-612 Lublin
}

Bryl M., Bis-Wencel H., Ślaska B., Nowakowicz-Dębek B., Bełkot Z., Kubik-Komar A. Relationship between body weight and leptin concentrations in mink dams and the birth parameters of kits

Summary

The aim of this study was to assess the impact of the leptin concentration and body weight of mink females on the birth parameters of their kits. Blood samples were collected 3 times during preparation for reproduction, $7 \pm 2$ days before mating. Total leptin concentration in serum was measured using commercial RIA kits (Millipore, St. Charles, Missouri USA). Research was conducted on 20 clinically healthy scanbrown female minks (Neovison vison) aged 2-3 years. To evaluate their body condition, the females were divided into two groups based on the BCS scoring system. In the first group, referred to as BCS 2, lean females were included, and the second group (BCS 4) consisted of obese females.

In mink dams belonging to BCS 2, the average leptin values were one-fourth of those in the BCS 4 group. The results obtained indicate the influence of the body mass of minks during preparation for reproduction on serum leptin concentration. The results of the Mann-Whitney $U$ test showed a statistically significant difference between weights and leptin concentrations in groups BCS 2 and BCS 4. Among the other traits, such differences were not found. The analysis of results obtained in the two mink groups did not reveal a clear relationship between leptin in the serum of mothers before mating and the birth parameters of their kits.

Keywords: mink, leptin, body mass

The mink (Neovison vison), a semi-aquatic carnivore, was introduced for fur farming in many parts of Europe in the early $20^{\text {th }}$ century (12). Minks as wild animals had to adapt to the cage, which limited their physical activity, but received access to food exceeding their normal intake in the wild. This situation is particularly noticeable in the perinatal period and in 2-6 weeks of lactation, and can often be manifested by the wet net disease, increased maternal mortality, destruction of the offspring, and metabolic syndrome in females (2). Similar to other seasonal breeders, minks have annual cycles of changes in food intake and body weight. During the winter months, their body weight decreases by $10-15 \%$ in ad libitum-fed dams. Furthermore, reproduction in minks is strictly regulated by photoperiod, and the reproductive outcome is highly responsive to nutritional manipulation (13).
Minks have a tendency for seasonal fatness, and are very vulnerable to changes in energy supply. Besides, they store large fat amounts during autumn, which are mobilized during winter and spring (14). Therefore, the process of mink breeding faces the problem of conceiving after a period of declining body reserves. The reproductive performance of minks is highly responsive to energy supply especially in yearling females (the necessity of supporting growth and the viability of a large number of fetuses) (12-14). The dam gives birth to altricial young after a gestation comprising a short embryonic diapause followed by a true gestation period of 31 days (7). In minks, birth weight is strongly determined by the environment (3). The nutritional status and the quality of many active ingredients operating in the perinatal period and early extrauterine life affect the development of the hypo- 
thalamic structures involved in the control of appetite, energy expenditure, and metabolism. In extremely lean animals, the pre-ovulatory luteinizing hormone surge and ovulation can even be abolished (9). Hormones like leptin affect the metabolism of the mother, regulating the availability of nutrients to the fetus (4). On the other hand, plasma leptin concentrations correlate positively with the body fat content in humans $(4,11)$ and minks (14).

This work is a fragment of a broader study on the impact of susceptibility to obesity on metabolic disorders in mink females during the reproductive period. The aim of this study was to assess the impact of the leptin concentration and body weight of mink females on the birth parameters of their kits.

\section{Material and methods}

Research was conducted on 20 clinically healthy scanbrown female minks aged 2-3 years. To evaluate their body condition, the females were divided into two groups based on a BCS scoring system developed by Hynes (7), which is useful in assessing obesity in mink. In the first group, referred to as BCS 2, lean females weighing $922.3 \pm 15.6 \mathrm{~g}$ were included, and the second group BCS 4 consisted of obese females with a weight of $1315 \pm 12.1 \mathrm{~g}$. The animals received a balanced fodder in the period from December to February: ME-4811 kJ/kg (\%ME 52.0 from protein, 36.0 from fat 12.0 from carbohydrates), and from March to weaning: ME $5230 \mathrm{~kJ} / \mathrm{kg}$ (\%ME 45.0 from proteins 43.0 from fat, 12.0. from carbohydrates). The ration size was determined independently, in accordance with current food standards, depending on the condition of the animals (10). The animals were provided with continuous access to water. Blood samples were collected 3 times during preparation for reproduction, $7 \pm 2$ days before mating, always at the same time before feeding and watering, into plain $5 \mathrm{ml}$ tubes and allowed to clot for 15 minutes at $36^{\circ} \mathrm{C}$. After clotting, the tubes were centrifuged at $1.500 \times \mathrm{g}$ for $15 \mathrm{~min}$. Serum was aliquoted and frozen at $-80^{\circ} \mathrm{C}$. Serum total leptin concentrations were measured using commercial RIA kits (Millipore, St. Charles, Missouri USA). Samples were run in duplicate and counted in a gamma counter (Agroecological Laboratory in Lublin). Serum concentrations of leptin were determined by radioimmunoassay (Multi-Species Leptin RIA kit; Millipore, St Charles, Missouri, USA) previously validated for mink plasma. The Multi-Species Leptin assay utilizes ${ }^{125}$ I-labeled Human Leptin with a specific activity of $135 \mu \mathrm{Ci} / \mu \mathrm{g}$, with normal guinea pig IgG as a carrier, and goat anti-guinea pig IgG serum, 3\% PEG and $0.05 \%$ TritonX-100 in 0.005M Phosphosaline, 0.025M EDTA in the precipitating reagent. All samples were run in one assay, and the within-assay $\mathrm{CV}$ estimated from the precision profile was $10 \%$ for concentrations between 1 and $10 \mathrm{ng} / \mathrm{ml}$.

The results obtained were subjected to statistical analysis. Arithmetic means $(\overline{\mathrm{x}})$ and standard deviations (SD) were calculated. In order to determine the interdependence of the traits studied, the Pearson correlation coefficient was calculated for BCS 2 and BCS 4. Because of the small sample size and the discrete nature of certain variables, a nonparametric Mann-Whitney U test was used to determine significant differences in these traits between all tested minks. In all tests, the level of significance $\alpha=0.05$ was adopted. All calculations were performed using STATISTICA version 10.

\section{Results and discussion}

Mean values of total leptin are presented in Table 1. Those differences were statistically significant at $\mathrm{P} \leq 0.05$. In the case of leptin, the values obtained from lean females $(3.09 \mathrm{ng} / \mathrm{ml})$ were almost one-fourth of the values obtained from obese minks $(12.42 \mathrm{ng} / \mathrm{ml})$, which was statistically important at $\mathrm{P} \leq 0.05$. The values of body weight and litter size for lean (BCS 2) and obese (BCS 4) mink dams are included in Table 2. The average total born litter size was 72 in lean dams and 71 in obese dams, of which, respectively, 64 and 67 kits were born alive. The mean live litter body weight at birth was lower for lean dams $(10.89 \mathrm{~g})$ than it was for obese dams $(11.17 \mathrm{~g})$. From then on, kits gained weight at a normal rate and reached live weights of $124.6 \mathrm{~g}$ (for lean dams) and $116.20 \mathrm{~g}$ (for obese dams) on $21^{\text {st }}$ day after birth. Stillborn kits constituted $11 \%$ of the total born ( 8 kits of lean dams) and 5.5\% (4 kits of obese dams). The mortality rate of offspring between $7^{\text {th }}$ and $21^{\text {st }}$ day of rearing was lower in the BCS 2 group (5 individuals) than in the BCS 4 group (8 individuals).

Tab. 1. Values of serum total leptin concentration $(\mathrm{ng} / \mathrm{mL})$ in mink females $7 \pm 2$ days before mating $(\overline{\mathbf{x}} \pm \mathrm{SD})$

\begin{tabular}{|c|c|}
\hline \multicolumn{2}{|c|}{ Females } \\
lean & obese \\
\hline $3.09^{\mathrm{a}} \pm 1.38$ & $12.42^{\mathrm{b}} \pm 5.35$ \\
\hline
\end{tabular}

Explanations: ${ }^{\mathrm{a}, \mathrm{b}}$ - mean values differ significantly at $\mathrm{P} \leq 0.05$

Tab. 2. Values of body weight and litter size for lean (BCS 2, $\mathrm{n}=10)$ and obese $(\mathrm{BCS} 4, \mathrm{n}=10) \mathrm{mink}$ dams

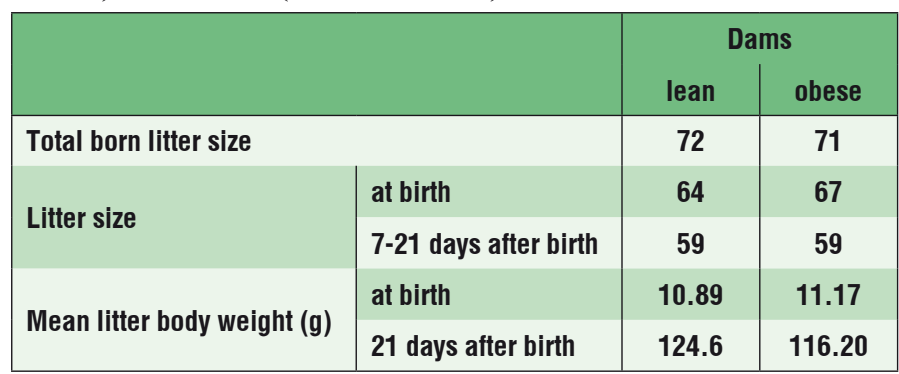

The analysis of relationships between the parameters in the group BCS 2 (Tab. 3), revealed negative correlations between the number of live-born kits in the litter and the maternal weight $(-0.64)$ and leptin levels $(-0.77)$. A negative correlation $(-0.60)$ was also observed between the weight of the mother and the number of deaths between $7^{\text {th }}$ and $21^{\text {st }}$ day. A positive correlation was found between the number of offspring born and the number of live individuals in the litter (0.72). In BCS 4 (Tab. 4), the mother's weight correlated positively with the mortality of cubs between $7^{\text {th }}$ and $21^{\text {st }}$ day after birth (0.67). In addition, leptin levels correlated positively with the average body weight of cubs on $21^{\text {st }}$ day after birth $(0.73)$. In all mink dams 
Tab. 3. Pearson correlation coefficients for the BCS 2 group

\begin{tabular}{|c|c|c|c|c|c|c|c|c|}
\hline Parameters & $\begin{array}{l}\text { Body weight } \\
\text { of dams }(\mathrm{g})\end{array}$ & Leptin & $\begin{array}{l}\text { Total born } \\
\text { litter size }\end{array}$ & Dead & Alive & $\begin{array}{l}\text { Mean litter } \\
\text { body weight } \\
\text { (g) }\end{array}$ & $\begin{array}{l}\text { Mean body } \\
\text { weight } 21 \text { days } \\
\text { after birth }\end{array}$ & $\begin{array}{l}\text { Dead 7-21 } \\
\text { days after } \\
\text { birth }\end{array}$ \\
\hline Body weight of dams (g) & 1.00 & 0.57 & -0.33 & 0.44 & -0.64 & -0.15 & 0.25 & -0.60 \\
\hline Leptin & & 1.00 & -0.52 & 0.38 & -0.77 & -0.49 & -0.40 & 0.23 \\
\hline Total born litter size & & & 1.00 & 0.31 & 0.72 & 0.29 & 0.04 & -0.06 \\
\hline Dead & & & & 1.00 & -0.44 & -0.16 & 0.12 & -0.16 \\
\hline Alive & & & & & 1.00 & 0.39 & -0.04 & 0.06 \\
\hline Mean litter body weight (g) & & & & & & 1.00 & 0.08 & -0.29 \\
\hline Mean body weight 21 days after birth & & & & & & & 1.00 & -0.57 \\
\hline Dead 7-21 days after birth & & & & & & & & 1.00 \\
\hline
\end{tabular}

Tab. 4. Pearson correlation coefficients for the BCS 4 group

\begin{tabular}{|c|c|c|c|c|c|c|c|c|}
\hline Parameters & $\begin{array}{l}\text { Body weight } \\
\text { of dams ( } \mathrm{g} \text { ) }\end{array}$ & Leptin & $\begin{array}{l}\text { Total born } \\
\text { litter size }\end{array}$ & Dead & Alive & $\begin{array}{l}\text { Mean litter } \\
\text { body weight } \\
\text { (g) }\end{array}$ & $\begin{array}{l}\text { Mean body } \\
\text { weight } 21 \text { days } \\
\text { after birth }\end{array}$ & $\begin{array}{l}\text { Dead 7-21 } \\
\text { days after } \\
\text { birth }\end{array}$ \\
\hline Body weight of dams (g) & 1.00 & 0.53 & 0.10 & -0.19 & 0.16 & 0.40 & 0.39 & 0.67 \\
\hline Leptin & & 1.00 & -0.27 & 0.23 & -0.35 & 0.30 & 0.73 & 0.51 \\
\hline Total born litter size & & & 1.00 & 0.18 & 0.95 & 0.03 & -0.46 & 0.38 \\
\hline Dead & & & & 1.00 & -0.13 & -0.19 & 0.16 & -0.24 \\
\hline Alive & & & & & 1.00 & 0.09 & -0.51 & 0.46 \\
\hline Mean litter body weight (g) & & & & & & 1.00 & 0.41 & 0.27 \\
\hline Mean body weight 21 days after birth & & & & & & & 1.00 & 0.23 \\
\hline Dead 7-21 days after birth & & & & & & & & 1.00 \\
\hline
\end{tabular}

Tab. 5. Pearson correlation coefficients for all mink dams

\begin{tabular}{|c|c|c|c|c|c|c|c|c|}
\hline Parameters & $\begin{array}{l}\text { Body weight } \\
\text { of dams }(\mathrm{g})\end{array}$ & Leptin & $\begin{array}{l}\text { Total born } \\
\text { litter size }\end{array}$ & Dead & Alive & $\begin{array}{l}\text { Mean litter } \\
\text { body weight } \\
\text { (g) }\end{array}$ & $\begin{array}{l}\text { Mean body } \\
\text { weight } 21 \text { days } \\
\text { after birth }\end{array}$ & $\begin{array}{c}\text { Dead } 7-21 \\
\text { days after } \\
\text { birth }\end{array}$ \\
\hline Body weight of dams (g) & 1.00 & 0.74 & -0.08 & -0.05 & -0.05 & 0.13 & 0.02 & 0.10 \\
\hline Leptin & & 1.00 & -0.33 & 0.15 & -0.40 & -0.10 & -0.04 & 0.37 \\
\hline Total born litter size & & & 1.00 & 0.24 & 0.84 & 0.18 & -0.19 & 0.15 \\
\hline Dead & & & & 1.00 & -0.32 & -0.19 & 0.13 & -0.20 \\
\hline Alive & & & & & 1.00 & 0.28 & -0.26 & 0.26 \\
\hline Mean litter body weight (g) & & & & & & 1.00 & 0.17 & -0.06 \\
\hline Mean body weight 21days after birth & & & & & & & 1.00 & -0.23 \\
\hline Dead 7-21 days after birth & & & & & & & & 1.00 \\
\hline
\end{tabular}

(Tab. 5) a positive correlation between body weight and leptin was observed (0.74).

The results of the MannWhitney U test showed a statistically significant difference between mother's weight and leptin in all minks. Among the other traits, such differences were not found (Tab. 6). Leptin is involved in the regulation of food intake, energy Tab. 6. Results of the Mann-Whitney $U$ test for BCS 2 and BCS 4

\begin{tabular}{|l|r|r|r|r|c|}
\hline \multicolumn{1}{|c|}{ Parameters } & Sum.rang & Sum.rang & U & \multicolumn{1}{c|}{ Z } & p \\
\hline Body weight & 55.000 & 155.000 & 0.000 & -3.742 & 0.000 \\
Leptin & 67.000 & 143.000 & 12.000 & -2.835 & 0.005 \\
Total born litter size & 110.000 & 100.000 & 45.000 & 0.340 & 0.734 \\
Dead & 107.000 & 103.000 & 48.000 & 0.113 & 0.910 \\
Alive & 101.000 & 109.000 & 46.000 & -0.265 & 0.791 \\
Mean litter body weight (g) & 87.500 & 122.500 & 32.500 & -1.285 & 0.199 \\
Mean body weight 21 days after birth & 114.000 & 96.000 & 41.000 & 0.643 & 0.521 \\
Dead 7-21 days after birth & 93.000 & 117.000 & 38.000 & -0.869 & 0.385 \\
\hline
\end{tabular}

homeostasis, immunity, and

reproduction. Leptin is produced primarily in white adipose tissue and acts via a family of membrane-bound receptors, including an isoform with a long intracellular domain (OB-Rb), and many isoforms with short 
intracellular domains (Ob-Rs) $(1,8)$. Furthermore, leptin administration has been shown to accelerate the onset of puberty in rodents. It has been proposed that leptin acts as a general signal of low energy status to the neuroendocrine axes; leptin administration reverses changes in levels of thyrotropin, adrenocorticotrophic hormone and gonadotropins caused by fasting in mice (5). It has been shown that leptin is also involved in the adaptation of the organism to life under extrauterine conditions and affects body weight control. Leptin inhibits the stress response by increasing the expression of glucocorticoid receptors in the central nervous system and increases the sensitivity to an inhibitory concentration of glucocorticoids. Another, although less efficient source of leptin for the child, is the placenta (9). An important dimension is the fact that the placenta contains leptin receptors and is also the place where this hormone is produced. Leptin can be both a growth factor and a signal of energy status between the mother and the fetus (14). It is also believed that leptin is involved in the normal development of the embryo and fetus and that its concentration during parturition is positively correlated with birth weight (9). Recent reports indicate that leptin activates the release of pro-inflammatory cytokines and prostaglandins from the human placenta, thus indicating leptin as a modulator of the placenta endocrine function (14).

The synthesis of leptin in the fetus begins in the first trimester of pregnancy with the development of adipose tissue and significantly increases at the end of the third trimester. It has been proven that leptin, in addition to regulating body weight, affects the development of many tissues and systems, including the skeletal, respiratory, gastrointestinal, and hematopoetic system (4). Fertility in mammals requires adequate nutrition and metabolic reserves. People with a major dietary restriction (anorexia nervosa, insulin dependent diabetes, cachexia) suffer from a significant impairment of the reproductive system. It is postulated that leptin may inform the reproductive axis of the nutritional status of the body, preventing maturation and reproduction if sufficient metabolic reserves are not available. A reduced expression of leptin increases the activity of neuropeptide Y (NPY), which exerts an inhibitory effect on the gonadotropin axis, via reduction in gonadotropin-releasing hormone $(\mathrm{GnRH})$ release follicle stimulating hormone (FSH) and lutropin (LH), which control hormonal and generative gonadal function. The receptor for leptin is expressed in the human ovary, and leptin is present in the follicular fluid. What is more, circulating leptin concentrations are associated with the phase of the menstrual cycle. Peak concentrations of leptin are found in the period of ovulation and in the luteal phase. Although it is not fully explained, it is believed that leptin affects the menstrual cycle and prepares the body for pregnancy (9). Reproduction in minks is highly dependent on the photoperiod. Prolactin, which is luteotrophic in minks, starts to rise over basal concentrations about the time of the vernal equinox, which might be permissive for the increase in food intake in the period of implantation because in mink dams that were not mated prolactin concentrations remained at basal levels, food intake was low, and the animals lost weight (14). Conversely, if exogenous prolactin implants were given to females that were not mated, food intake approached the level in mated females (13). Here the prolactin concentrations started to rise before those of leptin. In rats, prolactin may stimulate leptin synthesis, so it can be speculated that the photoperiod-dependent increase in plasma prolactin contributes to the induction of gestational hyperleptinaemia in the mink (13). Reduced energy nutrition during pregnancy and birth in minks is especially important to avoid overfeeding. Animals should be physically active because movement stimulates appetite and at the same time causes the loss of energy. Recent studies suggest restrictive feeding during the last days of pregnancy and the first two weeks of lactation (3). A study by Tauson (14) showed that fluctuations in body weight in response to food restriction and refeeding to a great extent reflected changes in body fat stores, and thereby confirmed that circulating leptin monitors body fat mass in minks, as well as in rodents and human subjects $(5,14)$. Increased levels of leptin obtained by Houseknecht et al. (6) suggest that obesity results from resistance to leptin, and therefore resistance to leptin could play a role in obesity. It should be noted that leptin has a direct and indirect effect on the mobilization and synthesis of lipids by adipocytes. In rats, leptin stimulates apoptosis of adipocytes and is involved in carbohydrate metabolism (1). Houseknecht et al. (6) indicate that the expression of leptin and its secretion are correlated with adipose tissue mass and the size of fat cells. Leptin can also directly affect the metabolism and function of peripheral tissues, such as the liver and the skeletal muscles, because leptin receptors are present on them (1). There is evidence that monocytes that transform into macrophages reside in fat tissue and can be the source of pro-inflammatory cytokine generation both locally and in the systemic circulation. Sex-dependent differences were also found by Baile et al. (1). The subcutaneous adipose tissue of women contains higher levels of leptin in comparison with that of men. Also, the amplitude of leptin is higher in women than in men and is correlated with BMI. In rats, males have a higher leptin concentration than females (1).

The present research showed the relationship between the concentration of leptin and the number and birth weight of the offspring. Tauson and Forsberg (13) showed that leptin levels in pregnant minks were lower than in unmated minks. However, in each case the concentration of leptin in plasma reflected body fat mass, which was also confirmed in our research. The level of leptin $(12.42 \mathrm{ng} / \mathrm{ml})$ and the birth weight of kits were higher in the BCS4 group. Similar results were 
obtained by Havel (5) in humans. Also Bury et al. (4) confirmed the importance of leptin as an indicator of nutrition in their research on plasma leptin concentrations in human neonates.

The results obtained in the present study suggest that the body mass of minks preparing for reproduction influences the serum leptin concentration. The analysis of results obtained in both mink groups did not reveal a clear relationship between leptin in the serum of mothers before mating and the birth parameters of their kits.

\section{References}

1. Baile C. A., Della-Fera M. A., Martin R. J.: Regulation of Metabolism and Body Fat Mass by Leptin. Annu. Rev. Nutr. 2000, 20, 105-127.

2. Bis-Wencel H.: Glucose level in blood and urine of minks depending on body condition. Ann. UMCS 2011, 29, 14-20.

3. Bis-Wencel H., Popiolek-Pyrz M., Matryna J., Holoda E.: The Effect of Diet on Biochemical Blood Parameters in Minks. Ann. UMCS, Lublin 2006, 24, 391-395.

4. Bury A., Kulik-Rechberger B., Migielska-Wolyniec M.: Relationships Between Leptin Concentration and Sex, Type of Delivery and Body Weight of Newborns During First Days of Life. Pediatr. Endocrinol. 2011, 10, 29-37.

5. Havel P. J.: Role of adipose tissue in body-weight regulation: mechanisms regulating leptin production and energy balance. Proc. Nutr. Soc. 2000, 59, 359-371.
6. Houseknecht K. L., Baile C. A., Matteri R. L., Spurlock M. E.: The biology of leptin: a review. J. Anim. Sci. 1998, 76, 1405-1420.

7. Hynes A. M., Rouvinen-Watt K., Armstrong D.: Body condition and glycemic control in mink females during reproduction and lactation. Proc. VIII Int. Sci. Congr. Fur Anim. Prod. The Netherlands, 15-18 September 2004, Scientifur 28, $79-86$

8. Ingvartsen K. L., Boisclair Y. R.: Leptin and the regulation of food intake, energy homeostasis and immunity with special focus on periparturient ruminants. Domest. Anim. Endocrinol. 2001, 21, 215-250.

9. Markowska A., Drews K., Malendowicz K.: Role of Leptin in Pathophysiology of Pregnancy. Adv. Clin. Exp. Med. 2003, 12, 811-816.

10. Nutritional recomendations and nutritive values of feed. Fur Animals. IFŻiZ, Jabłonna 2011

11. Ryökkynen A., Mustonen A. M., Pyykönen T., Hänninen S., Asikainen J., Jussi V. K. Kukkonen, Mononen J., Nieminen P.: Detection, Analysis and Interactions of Plasma Ghrelin, Leptin and Growth Hormone in the Mink (Mustela vison). Zool. Sci. 2003, 20, 1127-1132.

12. Schneider R. S., Hunter D. B.: A survey of the causes of mortality in adult mink, with emphasis on the lactation period. Can. Vet. J. 1993, 34, 103-108.

13. Tauson A. H., Forsberg M.: Body-weight changes are clearly reflected in plasma concentrations of leptin in female mink (Mustela vison). Brit. J. Nutr. 2002, 87, 101-105.

14. Tauson A. H., Forsberg M., Chwalibog A.: High leptin in pregnant mink (Mustela vison) may exert anorexigenic effects: a permissive factor for rapid increase in food intake during lactation. Brit. J. Nutr. 2004, 91, 411-421.

Corresponding author: Monika Bryl, PhD, Akademicka 13, 20-950 Lublin, Poland; e-mail: mbryl4@wp.pl 